\title{
PRODUKTIVITAS PEKERJA DALAM PEKERJAAN PEMASANGAN DINDING BATA DENGAN METODE CREW BALANCE CHART
}

\author{
Eddy Putra $^{1}$ dan Hendrik Sulistio ${ }^{2}$ \\ ${ }^{1}$ Program Studi Sarjana Teknik Sipil, Universitas Tarumanagara, Jl. Letjen S. Parman No.1 Jakarta \\ eddy.325150076@stu.untar.ac.id \\ ${ }^{2}$ Program Studi Sarjana Teknik Sipil, Universitas Tarumanagara, J1. Letjen S. Parman No.1 Jakarta \\ hendriks@ft.untar.ac.id
}

Masuk: 03-07-2020, revisi: 31-07-2020, diterima untuk diterbitkan: 31-07-2020

\begin{abstract}
The determination of the magnitude of value of productivity is the first step that must be conducted to determine magnitude of increase productivity that can be applied in construction projects. The determination of value of productivity requires the completeness of data obtained from workers data collection. Data collection displayed in form of Crew Balance Chart to get unproductive time and coefficient of workers based on field conditions in the installation of brick and to increase the productivity of workers on construction project of Residential Houses Cempaka Baru. Methods of data collection using observations in the field, as well as the data processed by using simple math. From the results of the research known to time is unproductive time of workers on the job installation of brick wall construction projects Cempaka Baru on front area is 9,711\%, and on back area is 48,737\% so it can be called that workers in the front area is quite productive while the workers in back area tend to be not productive. The productivity of workers front area amounted to $0,98 \mathrm{~m} 2 / \mathrm{h}$ while productivity in ideal conditions can reach 1,33 $\mathrm{m}^{2} / \mathrm{h}$, while that for back area the productivity $1,53 \mathrm{~m} 2 / \mathrm{h}$ while productivity ideally $2,25 \mathrm{~m} 2 / \mathrm{h}$.
\end{abstract}

Keywords: productivity; installation of brick walls; the crew balance chart

\begin{abstract}
ABSTRAK
Penentuan besarnya nilai produktivitas merupakan langkah awal yang harus dilakukan untuk mengetahui besarnya peningkatan produktivitas yang dapat diterapkan dalam proyek konstruksi. Penentuan nilai produktivitas memerlukan kelengkapan data yang didapat dari pendataan pekerja. Pendataan pekerja ini ditampilkan dalam bentuk diagram Crew Balance Chart untuk mendapatkan waktu tidak produktif dan koefisien pekerja berdasarkan kondisi lapangan dalam pekerjaan pemasangan dinding bata serta dapat meningkatan produktivitas pekerja pada proyek konstruksi Rumah Tinggal Cempaka Baru. Metode pengumpulan data dalam crew balance chart menggunakan observasi di lapangan, serta data diolah dengan menggunakan matematika sederhana. Dari hasil penelitian diketahui waktu tidak produktif pekerja pada pekerjaan pemasangan dinding bata proyek konstruksi Cempaka Baru pada area depan $9,711 \%$ dan pada area belakang 48,737\% sehingga dapat dapat disebut pekerja pada area depan cukup produktif sementara pekerja pada area belakang cenderung tidak produktif. Produktivitas pekerja pada area depan sebesar $0,98 \mathrm{~m}^{2} / \mathrm{jam}$ sedangkan produktivitas dalam kondisi ideal dapat mencapai $1,33 \mathrm{~m}^{2} / \mathrm{jam}$, sementara itu untuk area belakang produktivitasnya sebesar $1,53 \mathrm{~m}^{2} / \mathrm{jam}$ sedangkan produktivitas idealnya $2,25 \mathrm{~m}^{2} / \mathrm{jam}$.
\end{abstract}

Kata kunci: produktivitas; pemasangan dinding bata; crew balance chart

\section{PENDAHULUAN}

Dinding merupakan salah satu struktur bangunan yang berfungsi memisahkan dan membentuk ruangan. Selain itu dinding juga berfungsi untuk melindungi penghuni dari serangan hewan buas, hujan, panas matahari dan angin (Handayani).

Pada beberapa dekade ini terjadi perkembangan pada material dinding, salah satunya adalah bata ringan yang muncul sebagai alternatif pengganti bata merah pada konstruksi dinding. Inovasi bata ringan ini dikenal karena lebih cepat dan lebih murah namun memiliki kekurangan dari segi mutu dan ketahanan jika dibandingkan dengan bata merah (Tedja et al., 2014). Terdapat dua jenis bata ringan yang sering digunakan dalam proyek kontruksi khusus nya dalam pekerjaan pemasangan dinding bata, yaitu jenis AAC (Autoclaved Aerated Concrete), jenis ini sudah dapat diproduksi skala pabrik dan jenis kedua adalah CLC (Celluler Lightweight Concrete) (Kristiana and Pujiandi). 
Dalam kegiatan pelaksanaan proyek konstruksi termasuk pekerjaan dindng, produktivitas sangat berpengaruh untuk menghasilkan produk yang sesuai dengan rencana dalam hal waktu, mutu, dan biaya. Ada beberapa faktor yang mempengaruhi produktivitas, salah satunya adalah faktor tenaga kerja. Dalam pelaksanaan proyek konstruksi baik itu gedung maupun rumah tinggal tentunya tak lepas dari adanya sumber daya manusia, dari manajer proyek, petugas keamanan sampai para pekerja yang melakukan kegiatan-kegaitan di lapangan. Para pekerja atau biasa disebut dengan tukang inilah yang sangat berperan penting dalam proses dari proyek kontruksi dalam hal mutu, biaya dan waktu.

Penentuan besarnya nilai produktivitas merupakan langkah awal yang harus dilakukan untuk mengetahui besarnya peningkatan produktivitas yang dapat diterapkan dalam proyek konstruksi. Peningkatan produktivitas merupakan usaha untuk memperbaiki produktivitas rencana yang ada sehingga dapat meningkatkan hasil, manfaat maupun keuntungan dalam jumlah optimal (Rustendi).

Menentukan produktivitas, banyak sekali mengalami kesulitan karena produktivitas tidak bisa diukur secara akurat melainkan hanya dapat melalui pendekatan (Han and Leong). Penentuan nilai produktivitas memerlukan kelengkapan data yang didapat dari pendataan pekerja. Pendataan pekerja ini dapat dimanfaatkan untuk evaluasi kinerja dan data tersebut ditampilkan dalam bentuk diagram Crew Balance Chart.

Produktivitas pekerja dalam proses pelaksanaan konstruksi sangat penting agar pekerjaan dapat diselesaikan dalam waktu yang yang sudah direncanakan. Tetapi di lapangan tentunya banyak sekali faktor-faktor yang dapat membuat seorang tenaga kerja menjadi tidak produktif, seperti kondisi pekerja yang kurang sehat, banyak waktu yang diluangkan untuk merokok dan sebagainya. Dengan pendataan pekerja yang ditampilkan dalam diagram Crew Balance Chart dapat diupayakan peningkatan produktivitas dari tenaga kerja pada pekerjaan proyek konstruksi.

Tujuan dari penelitian ini adalah mendapatkan waktu tidak produktif dan koefisien pekerja berdasarkan kondisi lapangan dengan diagram crew balance chart pada pekerjaan proyek konstruksi rumah tinggal cempaka baru dan mendapatkan produktivitas pekerja pada proyek konstruksi rumah tinggal cempaka baru.

Batasan dalam penelitian ini adalah pengamatan dilakukan pada pekerjaan pemasangan dinding batu bata pada proyek konstruksi rumah tinggal Cempaka Baru, perhitungan akan dilakukan dengan data yang sesuai degnan kondisi lapangan pada pekerjaan proyek konstruksi rumah tinggal Cempaka Baru, perhitungan produktivitas dilakukan dengan pemodelan crew balance chart.

\section{Pekerjaan pemasangan dinding bata ringan}

Bata ringan atau yang biasa disebut dengan foamed concrete merupakan campuran dari mortar dengan foam agent dengan dilakukan kontrol terhadap campuran foam yang menjadikan densitas dari bata ini berada dikisaran 500 $1600 \mathrm{~kg} / \mathrm{m}^{3}$ (Jitchaiyaphum). Terdapat dua jenis bata ringan yang sering digunakan dalam proyek kontruksi khusus nya dalam pekerjaan pemasangan dinding bata, yaitu jenis AAC (Autoclaved Aerated Concrete), jenis ini sudah dapat diproduksi skala pabrik dan jenis kedua adalah CLC (Celluler Lightweight Concrete) (Kristiana and Pujiandi).

Bata ringan yang digunakan dalam proyek pembangunan rumah tinggal ini bermerek dagang Citicon dengan ukuran $60 \times 20 \times 10 \mathrm{~cm}$. Dalam proses pemasangan nantinya akan dikerjakan oleh dua orang pekerja, pekerja satu yang fokus tetap dalam persiapan dan pemasangan batu bata ringan dan pekerja dua yang membantu pekerja satu seperti mengaduk semen sebagai bahan perekat bata, mengangkat bata dari penyimpanan ke tempat pemasangan, serta memotong bata ringan sesuai dengan ukuran yang akan dipasang nantinya pada dinding.

Langkah-langkah dari pemasangan bata ringan menurut (Cahyo), sebagai berikut:

1. Siapkan sloof dan pondasi, tarik benang dan gunakan waterpass,

2. Buat lapisan dasar dengan semen instan dan lebarkan secara merata,

3. Letakan bata ringan di atas adukan semen,

4. Tekan permukaan bata ringan dengan palu agar rata sesuai dengan tarikan benang,

5. Periksa kerataan dengan menggunakan waterpass,

6. Rekatkan bagian vertikal bata ringan dengan Thin Bed Mortar,

7. Tarik benang dan gunakan waterpass,

8. Bersihkan permukaan bata ringan dari debu dan kotoran lainnya,

9. Letakkan adukan Thin Bed Mortar dengan trowel ke arah horizontal dan vertikal bata ringan, pastikan seluruh permukaan terlapisi dan jaga ketebalan dari adukan kira-kira $3 \mathrm{~mm}$,

10. Letakkan bata ringan diatas adukan dan ratakan dengan palu sampai sesuai dengan tarikan benang, pada saat meletakkan bata diatasnya diposisikan agar bata berada ditengah-tengah pada pertemuan bata dibawahnya (selang-seling). 


\section{Produktivitas}

Pengertian produktivitas dalam dunia konstruksi biasanya dihubungkan dengan produktivitas pekerja dan dapat dijabarkan sebagai perbandingan antara hasil kerja dan jam kerja. Produktivitas didefinisikan sebagai rasio antara output dengan input, atau rasio antara hasil produksi dengan total sumber daya yang digunakan. Dalam proyek konstruksi, rasio produktivitas adalah nilai yang diukur selama proses konstruksi, dapat dipisahkan menjadi biaya tenaga kerja, material dan alat (Ervianto).

(Ervianto) menjelaskan bahwa faktor-faktor yang mempengaruhi produktivitas proyek dapat dikelompokan dalam empat bagian utama, yaitu sebagai berikut:

1. Metode dan Teknologi

Terdiri dari faktor rekayasa, desain, metode pekerjaan, urutan kerja dan pengukuran kerja.

2. Manajemen Lapangan

Terdiri dari faktor perencanaan dan penjadwalan, komunikasi di lapangan, tata letak lapangan, manajemen eralatan, manajemen material dan manajemen tenaga kerja.

3. Lingkungan Kerja

Terdiri dari faktor lingkungan fisik, keselamatan kerja, keamanan kerja, latihan kerja, kualitas pengawasan dan partisipasi tenaga kerja.

4. Manusia

Terdiri dari faktor tingkat upah pekerja, kepuasan kerja, insentif, hubungan kerja antara mandor dan pekerja, kemangkiran.

Peningkatan produktivitas akan dianalisa guna untuk mendapatkan kondisi dimana waktu jam kerja dapat digunakan semaksimal mungkin, produktivitas sederhana dapat dihitung dengan perhitungan sederhana sesuai dengan rumus (1) berikut:

$$
\text { Produktivitas Ideal }=\frac{\% \text { waktu produktif maksimal }}{\text { rata }- \text { rata } \% \text { waktu produktif pekerja }} \times \text { produktivitas pekerja }
$$

Peningkatan produktivitas akan dilakukan hingga 100\% atau mencapai dalam kondisi ideal (Caroline).

\section{Observasi}

Menurut Young, observasi adalah suatu studi yang dilakukan dengan terencana dan sistematis yang mengamati, mencatat atau merekam kejadian-kejadian spontan yang terjadi pada saat pengamatan terjadi (Idea and Method of Legal Research). Observasi dilakukan untuk memperoleh informasi tentang kelakuan observe yang sebenarnya. Dengan demikian, melalui kegiatan observasi dapat diperoleh gambaran yang lebih jelas tentang kehidupan sosial atau kegiatan perilaku yang sukar diperoleh dengan metode lain. Observasi sangat diperlukan jika observer belum memiliki banyak keterangan tentang masalah yang diselidikinya. Sehingga observer dapat memperoleh gambaran yang jelas tentang masalahnya serta petunjuk-petunjuk cara menyelesaikannya (Mania).

Menurut (Herlina dkk, 2007) terdapat beberapa kelebihan dan kelemahan dari metode observasi, yaitu sebagai berikut:

$>$ Kelebihan Metode Observasi

1. Memungkinkan perekaman kegiatan-kegiatan pada saat terjadinya atau apa adanya.

2. Menghapus adanya keraguan dari kebenaran data karena dilakukan secara langsung.

3. Merupakan metode satu-satunya pada beberapa studi, seperti meneliti tingkah laku anak, hewan, dll.

4. Observasi tidak tergantung pada kemauan objek yang diobservasi untuk melaporkan atau menceritakan pengalamannya.

5. Mampu memahami tingkah laku yang kompleks dan situasi yang rumit.

6. Memperoleh gambaran berbagai tingkah laku dalam waktu yang bersamaan.

$>$ Kelemahan Metode Observasi

1. Observasi sangat tergantung pada individu yang melakukan pengamatan

- Terjadi Hallo Effect

Tanpa pengarahan yang terperinci akan diperoleh hasil yang sangat subjektif, dimana observer cenderung menilai seseorang dengan sikap menggeneralisasikan penilaian (positif atau negatif).

- Adanya refleksi observer

yaitu ikut berpengaruhnya struktur kepribadian observer (berkaitan dengan latar belakang observer), yang tercermin dalam hasil observasinya terhadap orang yang diobservasi. 
- Pengamatan bersifat selektif

Berkaitan dengan keterbatasan penglihatan secara fisiologis, juga berkaitan dengan minat dimana observer cenderung mengamati hal-hal yang menonjol atau yang ingin diamati saja.

2. Observasi dipengaruhi oleh responden yang diamati

Jika responden yang diamati mengetahui bahwa dirinya sedang diobservasi, bisa terjadi Hawthorne Effect, yaitu suatu kecenderungan pada individu untuk mengatur tingkah lakunya agar tampak menjadi lebih baik, sehingga menjadi berbeda dari kondisi yang alamiah.

3. Observasi bersifat terbatas

Observasi dilakukan dengan harus menunggu munculnya kegiatan yang ingin diamati.

4. Observasi terbatas oleh kurun waktu, contohnya meneliti riwayat hidup seseorang.

5. Observasi tidak mampu menggali ide, perasaan, sikap dan tanggapan seseorang.

6. Tidak banyak bidang yang dapat diteliti dengan menggunakan observasi sebagai metode utama.

7. Observasi tidak mampu menjelaskan dinamika tingkah laku.

8. Observasi yang menggunakan alat tentunya memerlukan biaya yang mahal, keahlian khusus untuk menggunakan alat tersebut serta dapat membuat kecurigaan atau merasa terganggu untuk yang diamati.

\section{Crew balance chart}

Crew balance chart merupakan metode untuk menampilkan data hasil pengamatan berbentuk diagram yang menunjukan durasi aktivitas pekerja yang berlanjut pada pekerjaan yang berulang. Tampilan dari diagram crew balance chart itu sendiri berbentuk seperti batang vertikal yang dibandingkan terhadap waktu yang digunakan. Batang vertikal tersebut di plot pada sumbu-X (Absis) yang dimana menunjukan tenaga kerja individual. Selain itu pada sumbu-Y (Ordinat) menunjukan subkegiatan yang dilakukan pekerja yang diamati, yang dimaksud dengan subkegiatan tersebut seperti waktu kegiatan produktif, dengan waktu tidak produktif. Pada ordinat Y menunjukan durasi dari pengamtan (menit, detik) atau persentase pada subkegiatan dalam pekerjaan tersebut (James J O'brien; Zilly; Robert G).

Jika dilihat dari penggambaran diagram crew balance chart menandakan semakin tinggi batang diagram tersebut, maka semakin lama waktu pengamatan yang dilakukan. Penggambaram diagram crew balance chart dapat dilihat pada gambar 1 sebagai berikut.

Figure 1
\begin{tabular}{|l|}
\hline standby/reposition \\
$\square$ shovel slurry \\
$\square$ direct slurry \\
$\square$ sandbag headwalls \\
$\square$ set pipe \\
$\square$ join pipes \\
$\square$ lift pipe \\
$\square$ hook pipe \\
$\square$ wait \\
$\square$ grade \\
$\square$ check grade \\
$\square$ cut \\
\hline
\end{tabular}

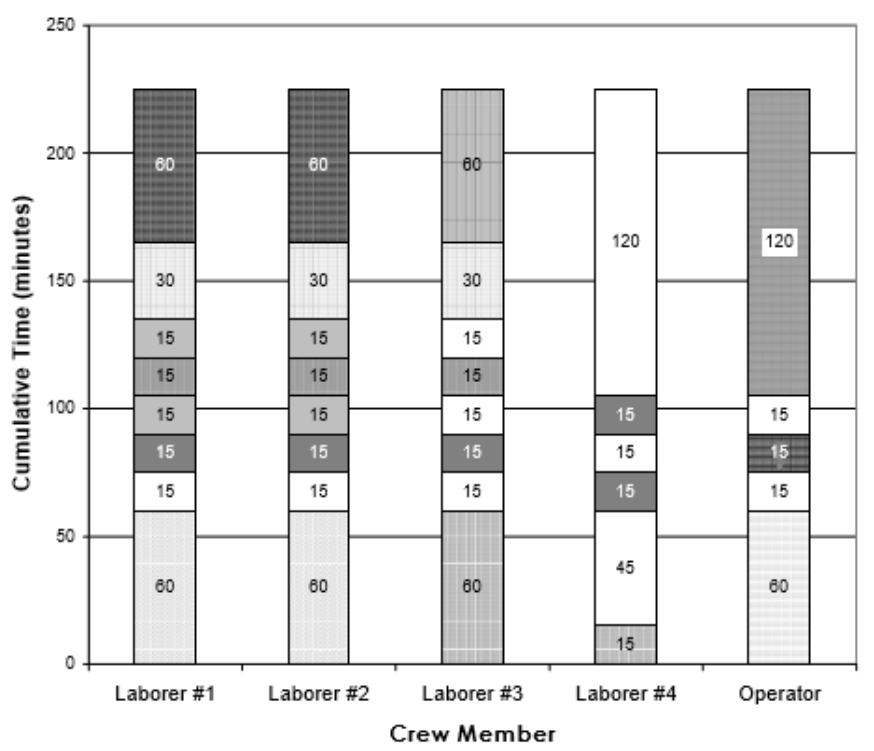

Gambar 1. Diagram crew balance chart (Sumber: (Kuprenas and Fakhouri))

Batang vertikal setiap tenaga kerja diplot dalam skala waktu yang sama, keterkaitan antar tenaga kerja dapat dipelajari dari perbandingan sepanjang garis sejajar sumbu X pada diagram tersebut. Pihak terkait dilapangan dapat menyusun tugas ulang guna untuk mengurangi jumlah pekerja atau menghilangkan waktu yang tidak produktif, agar dapat meningkatkan produktivitas. 
Crew Balance Chart digunakan untuk mendokumentasikan tenaga kerja yang sedang bertugas dan mengidentifikasi tindakan manajemen yang berpotensi untuk diubah atau bahkan menghemat waktu maupun sumber daya (material, tenaga kerja dan peralatan) dalam pekerjaan tersebut (Caroline). Langkah pengerjaan crew balance chart dibagi menjadi 5 langkah, yaitu sebagai berikut:

1. Mengidentifikasi pekerjaan berulang yang akan diperhitungkan.

7. Mengamati jumlah tenaga kerja dan kegiatan. Pencatatan dilakukan pada setiap subkegiatan dalam pekerjaan berulang tersebut.

8. Membuat grafis dari data yang dikumpulkan ke dalam diagram crew balance chart.

9. Menganalisa crew balance chart untuk mengidentifikasi hal yang berpotensi untuk perbaikan. Hal yang harus dilihat adalah jumlah tenaga kerja, pekerjaan tambahan, pekerjaan yang dilaksanakan, urutan pekerjaan yang dilakukan, penggunaan peralatan maupun material.

10. Menggunakan hasil dari analisa crew balance chart untuk mengidentifikasi potensi yang dapat digunakan untuk peningkatan dalam hal biaya, waktu, mutu, dan sebagainya.

\section{METODE PENELITIAN}

\section{Tempat penelitian}

Dalam penelitian ini dilakukan di salah satu proyek konstruksi Rumah Tinggal Cempaka Baru. Berikut adalah data umum proyek:

- Nama Proyek

- Lokasi Proyek

- Luas Lahan

- Luas Bangunan

- Jumlah Lantai
: Proyek Pembangunan Rumah Tinggal Cempaka Baru.

: Jalan Cempaka Baru No.2 VIII RT08/07, Kemayoran, Jakarta Pusat, DKI Jakarta.

: $200 \mathrm{~m}^{2}$

: $205 \mathrm{~m}^{2}$

: 2 Lantai

\section{Pengumpulan data}

Metode pengumpulan data dilakukan dengan menggunakan metode pengamatan dan wawancara. Pengamatan dilakukan dengan menggunakan alat bantu kamera video selama pekerjaan pemasangan dinding batu bata berlangsung. Pada saat pengamatan, terdiri dari dua orang, orang pertama bertugas untuk merekam dan menjaga kamera video yang digunakan sedangkan orang kedua bertugas untuk memantau pekerja bila si pekerja keluar dari layar kamera. Orang kedua berperan penting untuk kelangsungan pengamatan ini agar didapat data yang akurat, pekerja diamati apa yang dilakukan di luar daerah pekerjaan (buang air kecil, minum kopi dan lain-lain) dan langsung diinformasikan ke orang pertama untuk segera dicatat bila ada kegiatan yang dapat menghambat pekerja (mengobrol sesama pekerja, istirahat sebelum waktunya dan lain-lain).

Hasil pengamatan ditampilkan dalam bentuk diagram. Sementara itu, wawancara dilakukan kepada pekerja yang bersangkutan pada proyek kostruksi Rumah Tinggal Cempaka Baru. Dalam penelitian ini, tempat pengamatan dibagi menjadu dua area, yaiut area depan dan area belakang dimana, masing-masing area dilakukan pengamatan selama 2 hari. Diagram alir dari penelitian ini dapat dilihat pada gambar 2 dihalaman berikutnya. 


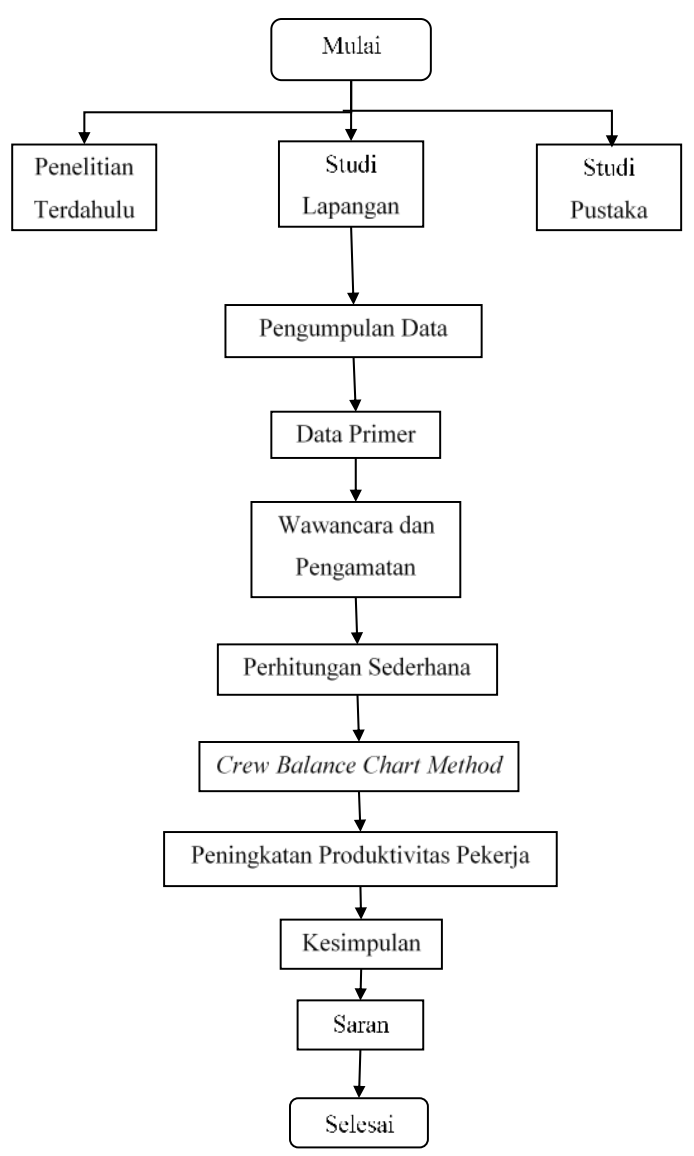

Gambar 2. Diagram alir

\section{Metode analisis data}

Analisis data dilakukan menjadi dua tahap, pertama dengan metode diagram Crew Balance Chart dan kemudian dilakukan peningkatan produktivitas pekerja. Pada diagram crew balance chart ditampilkan hasil data pengamatan dilapangan dari setiap subkegiatan pada pekerjaan pemasangan dinding. Dari data tersebut diolah untuk mendapatkan persentase waktu produktivitas pekerja dan persentase idle time yang terjadi. Untuk menghitung persentase waktu tidak produktif pekerja dapat menggunakan rumus (2) sebagai berikut:

$$
\text { Persentase Waktu Tidak Produktif }=\frac{\text { waktu tidak produktif pekerja dalam subkegiatan }}{\text { waktu total pekerjaan dalam subkegiatan }} \times 100 \%
$$

Hasil persentase tersebut ditampilkan dalam diagram crew balance chart. Diagram crew balance chart menampilkan persentase waktu produktif dan persentase waktu tidak produktif per satuan waktu, dari diagram tersebut ditampilkan tabel rumus rekapitulasi pekerjaan yang dapat dilihat pada Tabel 1. Tabel rumus rekapitulasi waktu pekerjaan

Tabel 1. Tabel rumus rekapitulasi waktu pekerjaan

\begin{tabular}{|c|c|c|c|c|c|c|c|}
\hline \multirow[t]{2}{*}{ Tenaga Kerja } & \multirow[t]{2}{*}{ Kegiatan } & \multicolumn{2}{|c|}{ Waktu Dasar } & \multicolumn{3}{|c|}{ Waktu Tidak Produktif } & \multirow[t]{2}{*}{ Koefisien (\%) } \\
\hline & & Pengamatan & Rata-Rata & Pengamatan & Rata-Rata & $\%$ & \\
\hline \multirow[t]{6}{*}{1} & \multirow[t]{6}{*}{ Pekerja } & $\mathrm{X}_{\mathrm{A} 1}$ & \multirow{2}{*}{$\left(\frac{X_{A 1}+X_{B 1}}{n}\right)$} & $\mathrm{Y}_{\mathrm{A} 1}$ & \multirow{2}{*}{$\left(\frac{Y_{A 1}+Y_{B 1}}{n}\right)$} & \multirow[t]{2}{*}{$Z_{1}$} & \multirow{7}{*}{$\frac{\sum\left(\frac{X_{A m}+X_{B m}}{n}\right)}{\text { waktu total kerja }}$} \\
\hline & & $\mathrm{X}_{\mathrm{B} 1}$ & & $\mathrm{Y}_{\mathrm{B} 1}$ & & & \\
\hline & & $X_{A 2}$ & \multirow{4}{*}{$\begin{array}{c}\left(\frac{X_{A 2}+X_{B 2}}{n}\right) \\
\left(\frac{X_{A m}+X_{B m}}{n}\right)\end{array}$} & $\mathrm{Y}_{\mathrm{A} 2}$ & \multirow{2}{*}{$\left(\frac{Y_{A 2}+Y_{B 2}}{n}\right)$} & \multirow[t]{2}{*}{$\mathrm{Z}_{2}$} & \\
\hline & & $X_{B 2}$ & & $\mathrm{Y}_{\mathrm{B} 2}$ & & & \\
\hline & & $X_{\text {Am }}$ & & $\mathrm{Y}_{\mathrm{Am}}$ & $\left(\underline{Y_{A m}+Y_{B m}}\right)$ & \multirow[t]{2}{*}{$Z_{m}$} & \\
\hline & & $\mathrm{X}_{\mathrm{Bm}}$ & & $\mathrm{Y}_{\mathrm{Bm}}$ & $(n)$ & & \\
\hline \multicolumn{3}{|c|}{ Rekapitulasi Waktu Total } & $\sum\left(\frac{X_{A m}+X_{B m}}{n}\right)$ & & $\sum\left(\frac{Y_{A m}+Y_{B m}}{n}\right)$ & $\sum Z$ & \\
\hline
\end{tabular}


Penjelasan mengenai variabel sebagai berikut:

$\mathrm{X}_{\mathrm{Am}} \quad=$ waktu dasar pekerja 1 saat jam A pada subkegiatan $\mathrm{m}$ ketika pengamatan

$\mathrm{X}_{\mathrm{Bm}} \quad=$ waktu dasar pekerja 1 saat jam $\mathrm{B}$ pada sub kegiatan m ketika pegamatan

$\mathrm{Y}_{\mathrm{Am}} \quad=$ waktu tidak produktif pekerja 1 pada saat jam A ketika pengamatan

$\mathrm{Y}_{\mathrm{Bm}} \quad=$ waktu tidak produktif pekerja 1 pada saat jam B ketika pengamatan

Dari diagram crew balance chart kita dapat mengetahui waktu produktivitasnya pekerja dan idle time pekerja. Dari data tersebut akan diolah untuk menentukan waktu ideal dari pekerjaan pemasangan dinding bata. Peningkatan produktivitas akan dianalisa guna untuk mendapatkan kondisi dimana waktu jam kerja dapat digunakan semaksimal mungkin, sesuai dengan rumus mencapai kondisi ideal (Caroline).

\section{HASIL DAN PEMBAHASAN}

\section{Hasil pengumpulan data}

Pengumpulan data pekerja pada pekerjaan pemasangan dinding bata dalam pembangunan rumah tinggal di daerah Cempaka Baru, Kemayoran, Jakarta dilakukan selama adanya pekerjaan yang ingin diamati dilaksanakan. Dalam pengamatan ini dilakukan selama 4 hari, dengan masing-masing 2 hari untuk setiap pasangan pekerja yang terbagi menjadi dua area yaitu area depan dan area belakang. Setiap pasangan pekerja dibagi menurut tugasnya masingmasing, pekerja satu yang berfokus untuk menyiapkan (menarik benang, membersihkan area yang ingin dipasangi bata), memasang dan menyusun bata, melapisi bata dengan adukan pebagai perekat. Sedangkan pekerja dua bertugas untuk membantu pekerja satu seperti menyiapkan adukan semen, mengangkat bata, memotong bata bila diperlukan. Pengamatan dilakukan pada setiap pekeja dan contoh hasil pengamatan dapat dilihat pada tabel 2 sebagai berikut:

Tabel 2. Contoh tabel hasil pengamatan pekerja pada area depan hari ke-1

\begin{tabular}{cccc}
\hline \multicolumn{2}{c}{ Waktu (Detik) } & \multicolumn{2}{c}{ Subkegiatan } \\
\hline Dari & Sampai & Pekerja 1 & Pekerja 2 \\
\hline 0 & 496 & Persiapan & Persiapan \\
496 & 601 & Persiapan & Aduk/Ambil Semen \\
601 & 866 & Persiapan & Angkat Bata \\
866 & 911 & Tunggu & Angkat Bata \\
911 & 1036 & Pasang & Aduk/Ambil Semen \\
1036 & 1070 & Tunggu & Aduk/Ambil Semen \\
1070 & 1101 & Pasang & Aduk/Ambil Semen \\
1101 & 1258 & Idle & Aduk/Ambil Semen \\
1258 & 1330 & Pasang & Aduk/Ambil Semen \\
1330 & 1341 & Pasang & Tunggu \\
1341 & 1352 & Pasang & Aduk/Ambil Semen \\
1352 & 1364 & Pasang & Tunggu \\
1364 & 1390 & Pasang & Idle
\end{tabular}

\section{Perhitungan dan rekapitulasi}

Perhitungan waktu produktif dan tidak produktif setiap pekerja digunakan dalam membuat rekapitulasi total waktu tidak produktif masing-masing pekerja, baik di area depan maupun di area belakang yang dapat dilihat pada Tabel 3 dan Tabel 4. Setelah itu, total persentase waktu tidak produktif setiap pekerja ditampilkan dalam rekapitulasi waktu kegiatan pekerja pada area depan di hari yang pertama seperti pada Tabel 5 serta menghasilkan koefisien tiap pekerja pada hari pertama. Pada rekapitulasi waktu kegiatan pekerja, persentase waktu tidak produktif dihitung setiap 30 menit (1800 detik) untuk mengetahui konsistensi dari pekerja.

Tabel 3. Rekapitulasi total waktu tidak produktif pada area depan

\begin{tabular}{cccc}
\hline \multirow{2}{*}{ Nama } & Jabatan & \multicolumn{2}{c}{ Persentase Total Waktu Tidak Produktif } \\
\cline { 3 - 4 } & & Hari ke-1 & Hari ke-2 \\
\hline 1 & Pekerja Pemasangan Dinding & 9,711 & 24,996 \\
2 & Pembantu Pekerja Pemasangan Dinding & 24,264 & 25,713 \\
\hline
\end{tabular}


Tabel 4. Rekapitulasi total waktu tidak produktif pada area belakang

\begin{tabular}{cccc}
\hline Nama & Jabatan & \multicolumn{2}{c}{ Persentase Total Waktu Tidak Produktif } \\
\cline { 3 - 4 } & & Hari ke-1 & Hari ke-2 \\
\hline A & Pekerja Pemasangan Dinding & 26,978 & 19,041 \\
B & Pembantu Pekerja Pemasangan Dinding & 36,415 & 48,737 \\
\hline
\end{tabular}

Tabel 5. Rekapitulasi waktu kegiatan pada area depan hari ke-1

\begin{tabular}{|c|c|c|c|c|c|c|}
\hline \multirow[t]{2}{*}{ Nama } & \multirow[t]{2}{*}{ Kegiatan } & \multicolumn{2}{|c|}{ Waktu Produktif } & \multicolumn{2}{|c|}{ Waktu Tidak Produktif } & \multirow{2}{*}{$\begin{array}{c}\text { Koefisien } \\
\%\end{array}$} \\
\hline & & Waktu (detik) & Observasi (detik) & Observasi (detik) & $\%$ & \\
\hline \multirow[t]{5}{*}{1} & \multirow[t]{5}{*}{ Pemasangan Dinding Bata } & $0-1800$ & 1564 & 236 & 3,072117 & \multirow[t]{6}{*}{90,28899} \\
\hline & & $1800-3600$ & 1706 & 94 & 1,22364 & \\
\hline & & $3600-5400$ & 1613 & 187 & 2,434262 & \\
\hline & & $5400-7200$ & 1607 & 193 & 2,512367 & \\
\hline & & $7200-7682$ & 446 & 36 & 0,468628 & \\
\hline & Total & & 6936 & 746 & 9,711013 & \\
\hline \multirow[t]{2}{*}{ Nama } & \multirow[t]{2}{*}{ Kegiatan } & \multicolumn{2}{|c|}{ Waktu Produktif } & \multicolumn{2}{|c|}{ Waktu Tidak Produktif } & Koefisien \\
\hline & & Waktu (detik) & Observasi (detik) & Observasi (detik) & $\%$ & $\%$ \\
\hline \multirow[t]{6}{*}{2} & \multirow[t]{5}{*}{ Pemasangan Dinding Bata } & $0-1800$ & 1702 & 98 & 1.275709 & \multirow[t]{6}{*}{75,73549} \\
\hline & & $1800-3600$ & 1233 & 567 & 7,38089 & \\
\hline & & $3600-5400$ & 1214 & 586 & 7,628222 & \\
\hline & & $5400-7200$ & 1306 & 494 & 6,430617 & \\
\hline & & $7200-7682$ & 363 & 119 & 1,549076 & \\
\hline & Total & & 5818 & 1864 & 24,26451 & \\
\hline
\end{tabular}

Contoh perhitungan akan dipakai pekerja 1 di area depan untuk hari pertama, yang hasilnya dapat dilihat pada Tabel 5. Pekerja 1 mempunyai waktu tidak produktif pada setengah jam pertama $=236$ detik, setengah jam kedua $=94$ detik, setengah jam ketiga $=187$ detik, setengah jam keempat $=193$ detik, dan sisa waktu terakhir $=36$ detik. Dari nilai waktu tidak produktif di atas dapat dihitung nilai persentase waktu tidak produktif dengan cara berikut:

Persentase Waktu Tidak Produktif $=\frac{\text { Total Waktu Tidak Produktif tiap setengah jam }}{\text { total } \text { waktu pekerjaan }} \times 100 \%$

Persentase waktu tidak produktif $1 / 2$ jam pertama $=\frac{236}{7682} \times 100 \%=3,0721 \%$

Persentase waktu tidak produktif $1 / 2$ jam kedua $=\frac{94}{7682} \times 100 \%=1,2236 \%$

Persentase waktu tidak produktif $1 / 2$ jam ketiga $=\frac{187}{7682} \times 100 \%=2,4342 \%$

Persentase waktu tidak produktif $1 / 2$ jam keempat $=\frac{193}{7682} \times 100 \%=2,5123 \%$

Persentase waktu tidak produktif sisa waktu terakhir $=\frac{36}{7682} \times 100 \%=0,4686 \%$

Total Persentase Waktu Tidak Produktif = Spersentase waktu tidak produktif setiap setengah jam

Total persentase waktu tidak produktif $=3,0721 \%+1,2236 \%+2,4342 \%+$

$$
2,5123 \%+0,4686 \%=9,711 \%
$$

Contoh perhitungan nilai koefisien pekerja 1:

Nilai Koefisien $=\frac{\text { Jumlah waktu produktif }}{\text { Jumlah } \text { waktu pekerjaan }} \times 100 \%$ 
Nilai Koefisien $=\frac{6936}{7682} \times 100 \%=90,2889 \%$

\section{Implementasi crew balance chart}

Implementasi pekerjaan pemasangan dinding bata pada proyek rumah tinggal Cempaka Baru bila dilihat pada crew balance chart di bawah dapat digolongkan menjadi 2 macam, pada Gambar 3 dan Gambar 4 yang menampilkan crew balance chart area depan dari proyek ini terlihat bahwa produktivitas dari pekerja cukup tinggi ditinjau dari waktu idle yang cukup sedikit meskipun mengalami penurunan pada hari yang kedua.

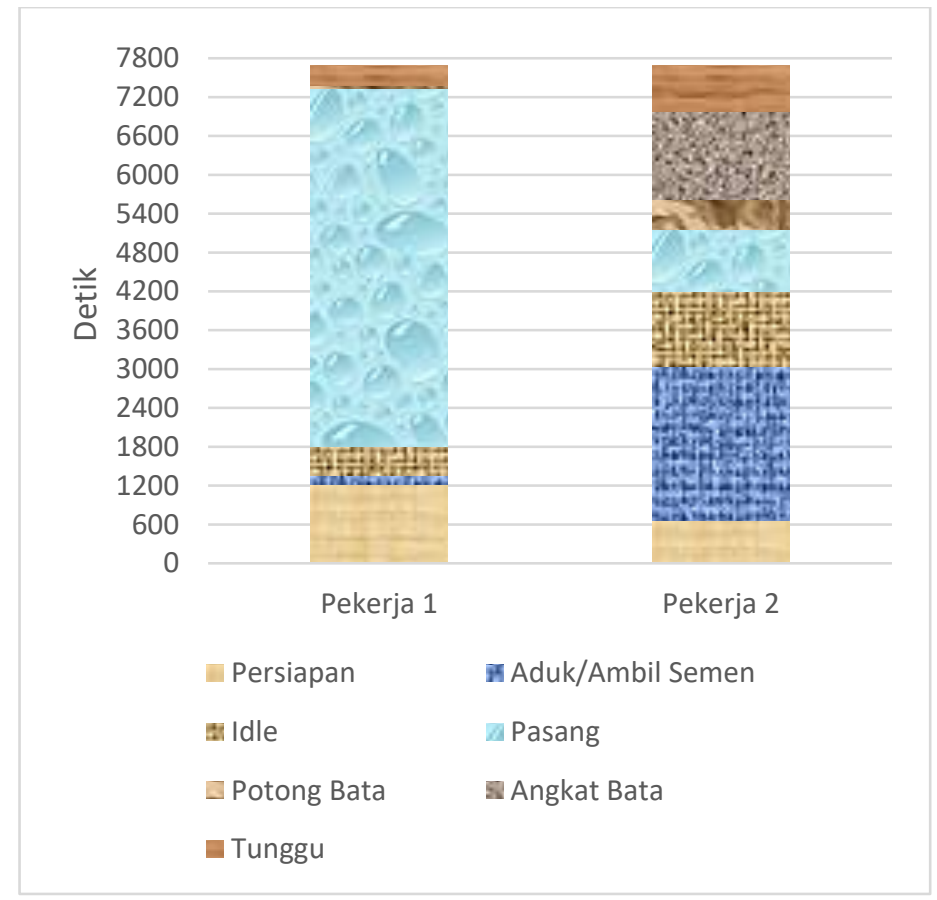

Gambar 3. Crew balance chart area depan hari ke-1

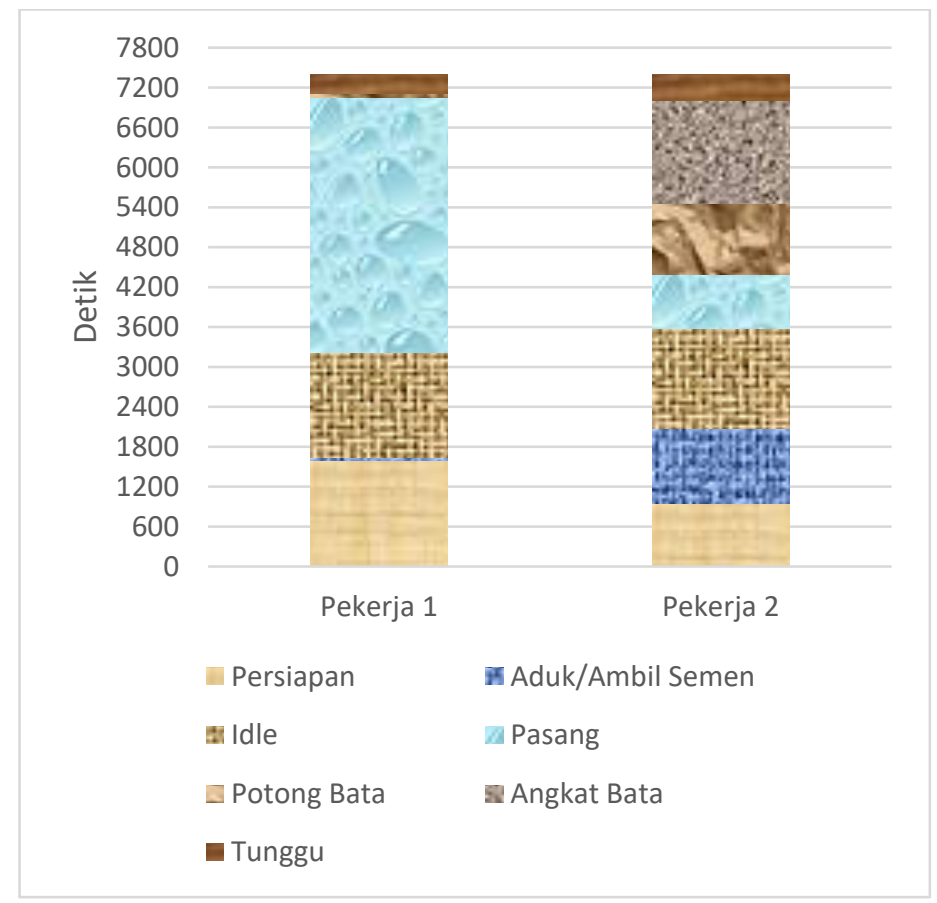

Gambar 4. Crew balance chart area depan hari ke-2 
Kemudian pada Gambar 5 dan Gambar 6 yang menampilkan crew balance chart area belakang proyek terlihat bahwa produktivitas dari pekerja rendah ditinjau dari waktu idle dan waktu untuk melakukan kegiatan yang lainnya yang sangat tinggi dan banyak.

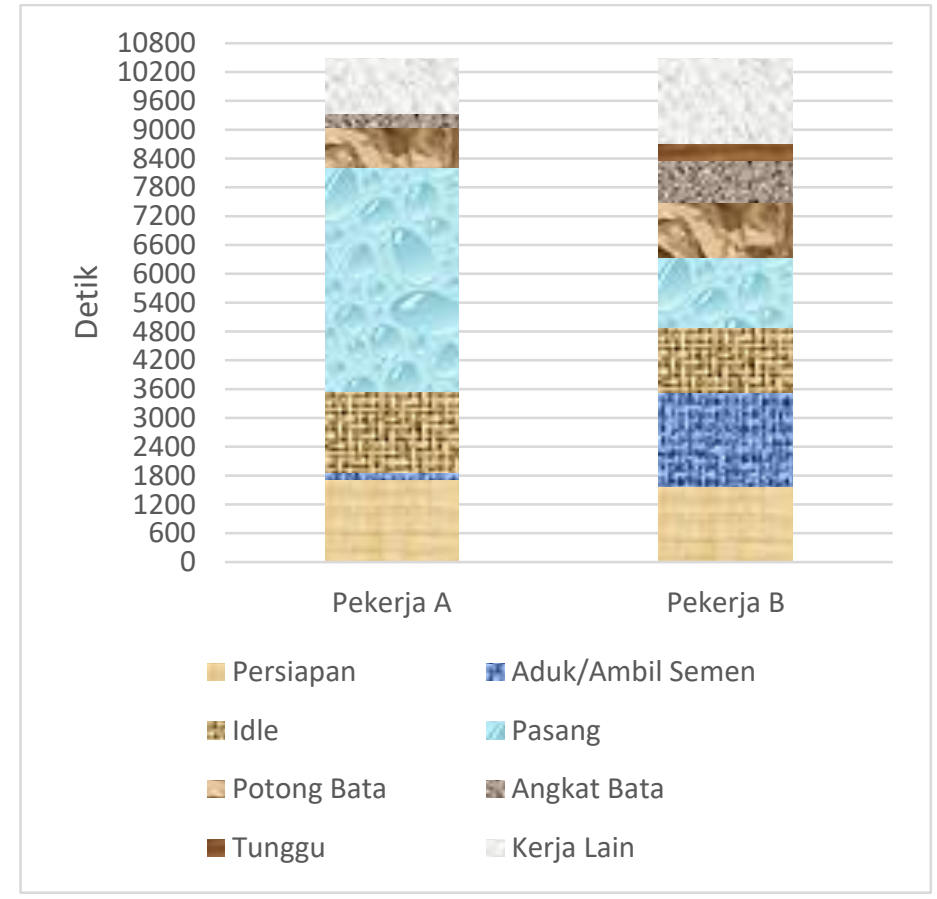

Gambar 5. Crew balance chart area belakang hari ke-1

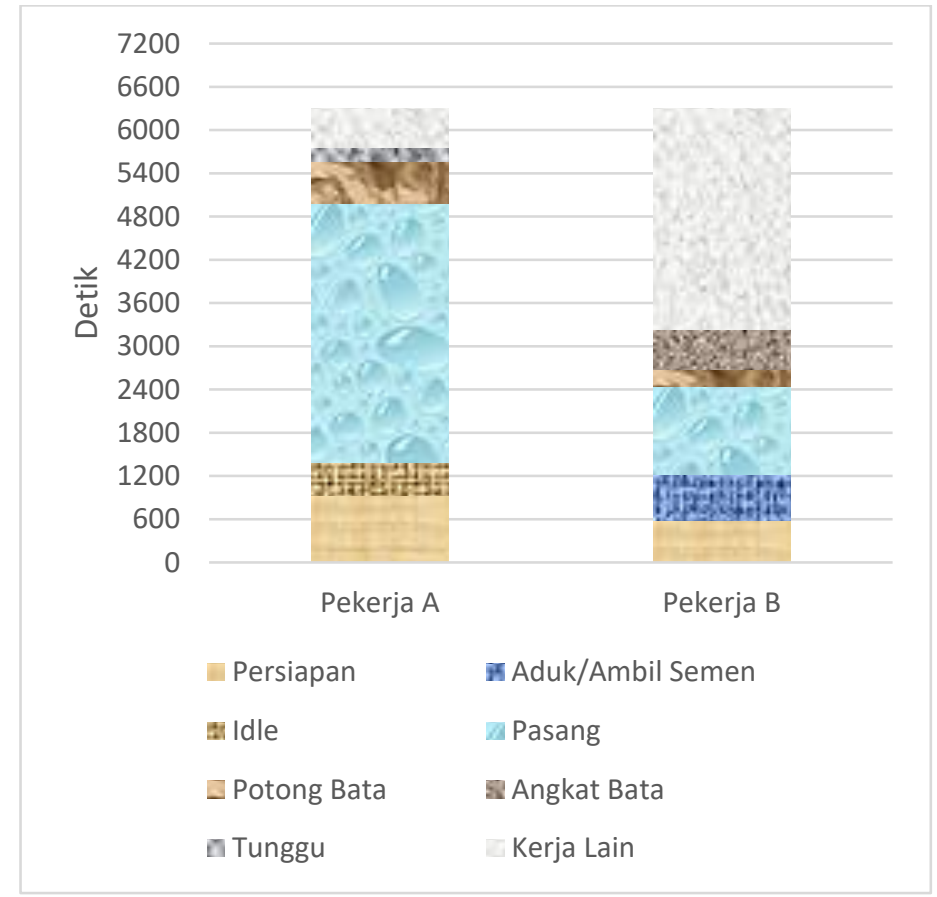

Gambar 6. Crew balance chart area belakang hari ke-2

Dari crew balance chart diatas dapat disimpulkan atau dapat dievaluasi kinerja dari para pekerja, untuk pekerja pada area depan dengan produktivitas yang ada sekarang perlu diberi pengawasan yang lebih lagi agar produktivitasnya dapat dipertahankan dan tidak mengalami penurunan. Sedangkan untuk pekerja area belakang, dilihat dari kinerja yang ada dengan idle yang tinggi perlu diberi pengawasan dan pengarahan atau masukan lagi supaya kinerja nya meningkat dan mandornya pun harus dapat lebih tegas atau lebih sistematis agar pekerja dapat menyelesaikan pekerjaan dengan tepat waktu, karena bila dilihat adanya faktor kerja kegiatan lain dalam crew balance chart yang 
tinggi ini mengindikasikan bahwa pekerjaan-pekerjaan sebelum pemasangan dinding bata ada yang belum selesai atau bahkan belum dikerjakan sehingga menghambat kegiatan pekerjaan pemasangan dinding bata.

\section{Perhitungan produktivitas}

Perhitungan produktivitas pekerja dibagi menjadi 2 yaitu produktivitas pekerja di lapangan dan produktivitas pekerja tanpa idle atau kondisi ideal.

1. Perhitungan Produktivitas Pekerja di Lapangan

Produktivitas pekerja yang dihitung diperoleh dari pengamatan yang dilakukan pada pekerjaan pemasangan dinding bata, dengan mengukur luasan dinding yang berhasil dikerjakan.

- Hari pertama Area Depan

$$
\begin{aligned}
\text { Produktivitas } & =\frac{\text { Total Luasan Dinding yang dikerjakan }}{\text { Total Durasi Pekerjaan }} \\
& =\frac{4,2 \mathrm{~m} \times 0,5 \mathrm{~m}}{7682 \mathrm{detik}} \times 3600 \\
& =0,9841 \mathrm{~m}^{2} / \mathrm{jam}
\end{aligned}
$$

- Hari kedua Area Depan

$$
\begin{aligned}
\text { Produktivitas } & =\frac{\text { Total Luasan Dinding yang dikerjakan }}{\text { Total Durasi Pekerjaan }} \\
& =\frac{(4,2 \mathrm{~m} \times 0,4 \mathrm{~m})+(1,8 \mathrm{~m} \times 0,2 \mathrm{~m})}{7393 \text { detik }} \times 3600 \\
& =0,9933 \mathrm{~m}^{2} / \mathrm{jam}
\end{aligned}
$$

- Hari pertama Area Belakang

$$
\begin{aligned}
\text { Produktivitas } & =\frac{\text { Total Luasan Dinding yang dikerjakan }}{\text { Total Durasi Pekerjaan }} \\
& =\frac{3,2 \mathrm{~m} \times 1,4 \mathrm{~m}}{10490 \mathrm{detik}} \times 3600 \\
& =1,537 \mathrm{~m}^{2} / \mathrm{jam}
\end{aligned}
$$

- Hari kedua Area Belakang

$$
\begin{aligned}
\text { Produktivitas } & =\frac{\text { Total Luasan Dinding yang dikerjakan }}{\text { Total Durasi Pekerjaan }} \\
& =\frac{3,2 \mathrm{~m} \times 0,4 \mathrm{~m}}{6297 \mathrm{detik}} \times 3600 \\
& =0,7317 \mathrm{~m}^{2} / \mathrm{jam}
\end{aligned}
$$

\section{Perhitungan Produktivitas Pekerja Tanpa Idle}

Berdasarkan data yang yang diperoleh diatas, persentase waktu produktif para pekerja cukup bervariasi tetapi tidak ada yang mencapai $100 \%$, oleh karena itu pada perhitungan ini akan menghitung produktivitas pekerja tanpa idle atau dengan kata lain menganggap waktu produktif mencapai 100\% (kondisi ideal).

- Hari pertama Area Depan

$$
\begin{aligned}
& \text { Produktivitas tanpa idle }=\frac{\% \text { waktu produktif ideal }}{\text { rata }- \text { rata } \% \text { waktu produktif pekerja }} \times \text { produktivitas pekerja di lapangan } \\
& \begin{aligned}
\text { Produktivitas tanpa idle }= & \frac{100 \%}{(90,2889 \%+75,7355 \%) / 2} \times 0,9841 \mathrm{~m}^{2} / \mathrm{jam} \\
= & 1,1855 \mathrm{~m}^{2} / \mathrm{jam}
\end{aligned}
\end{aligned}
$$

- Hari kedua Area Depan

Produktivitas tanpa idle $=\frac{\% \text { waktu produktif ideal }}{\text { rata }- \text { rata } \% \text { waktu produktif pekerja }} \times$ produktivitas pekerja di lapangan 


$$
\begin{aligned}
\text { Produktivitas tanpa idle } & =\frac{100 \%}{(75,0034 \%+74,2865 \%) / 2} \times 0,9933 \mathrm{~m}^{2} / \mathrm{jam} \\
& =1,3307 \mathrm{~m}^{2} / \mathrm{jam}
\end{aligned}
$$

- Hari pertama Area Belakang

$$
\begin{aligned}
& \text { Produktivitas tanpa idle }=\frac{\% \text { waktu produktif ideal }}{\text { rata }- \text { rata } \% \text { waktu produktif pekerja }} \times \text { produktivitas pekerja di lapangan } \\
& \text { Produktivitas tanpa idle }=\frac{100 \%}{(73,0219 \%+63,5843 \%) / 2} \times 1,537 \mathrm{~m}^{2} / \mathrm{jam} \\
& =2,2502 \mathrm{~m}^{2} / \mathrm{jam}
\end{aligned}
$$

- Hari kedua Area Belakang

$$
\begin{aligned}
& \text { Produktivitas tanpa idle }=\frac{\% \text { waktu produktif ideal }}{\text { rata }- \text { rata } \% \text { waktu produktif pekerja }} \times \text { produktivitas pekerja di lapangan } \\
& \begin{aligned}
\text { Produktivitas tanpa idle }= & \frac{100 \%}{(80,9592 \%+51,2625 \%) / 2} \times 0,7317 \mathrm{~m}^{2} / \mathrm{jam} \\
= & 1,1067 \mathrm{~m}^{2} / \mathrm{jam}
\end{aligned}
\end{aligned}
$$

\section{Analisa peningkatan produktivitas}

Dari hasil perhitungan produktivitas tanpa idle diperoleh nilai produktivitas yang cukup jauh berbeda dari perhitungan produktivitas di lapangan, khususnya pada area belakang dimana pada hari pertama produktivitas di lapangan sebesar 1,537 m²/jam sementara produktivitas tanpa idle sebesar 2,2502 $\mathrm{m}^{2} / \mathrm{jam}$. Berdasarkan data ini, dilakukan perhitungan waktu yang diperlukan bila produktivitas ditingkatkan atau tanpa adanya idle.

- Hari pertama Area Depan

$$
\begin{aligned}
\text { Durasi Kerja Tanpa Idle } & =\frac{\text { produktivitas di lapangan }}{\text { produktivitas tanpa idle }} \times \text { total waktu kerja } \\
& =\frac{0,9841 \mathrm{~m}^{2} / \mathrm{jam}}{1,1855 \mathrm{~m}^{2} / \mathrm{jam}} \times 7682 \text { detik } \\
& =6376,934 \text { detik }
\end{aligned}
$$

- Hari kedua Area Depan

$$
\begin{aligned}
\text { Durasi Kerja Tanpa Idle } & =\frac{\text { produktivitas di lapangan }}{\text { produktivitas tanpa idle }} \times \text { total waktu kerja } \\
& =\frac{0,9933 \mathrm{~m}^{2} / \mathrm{jam}}{1,3307 \mathrm{~m}^{2} / \mathrm{jam}} \times 7393 \text { detik } \\
& =5518,499 \text { detik }
\end{aligned}
$$

- Hari pertama Area Belakang

$$
\begin{aligned}
\text { Durasi Kerja Tanpa Idle } & =\frac{\text { produktivitas di lapangan }}{\text { produktivitas tanpa idle }} \times \text { total waktu kerja } \\
& =\frac{1,537 \mathrm{~m}^{2} / \mathrm{jam}}{2,2502 \mathrm{~m}^{2} / \mathrm{jam}} \times 10490 \text { detik } \\
& =7165,198 \text { detik }
\end{aligned}
$$

- Hari kedua Area Belakang

$$
\begin{aligned}
\text { Durasi Kerja Tanpa Idle } & =\frac{\text { produktivitas di lapangan }}{\text { produktivitas tanpa idle }} \times \text { total waktu kerja } \\
& =\frac{0,7317 \mathrm{~m}^{2} / \mathrm{jam}}{1,1067 \mathrm{~m}^{2} / \mathrm{jam}} \times 6297 \text { detik } \\
& =4163,291 \text { detik detik }
\end{aligned}
$$

Berdasarkan perhitungan diatas, dapat diperoleh penghematan waktu yang cukup jauh diantara rentang 1000-3000 detik atau sekitar 16 sampai 56 menit. Sebagai contoh diambil pada hari pertama di area belakang, durasi waktu 
kerja di lapangan sebesar 10490 detik sementara bila tanpa idle durasi nya hanya 7165 detik berselisih sekitar 3325 detik atau sekitar 56 menit. Tentunya dengan meningkatkan produktivitas dari pekerja waktu sekitar 56 menit ini dapat dimanfaatkan oleh pekerja untuk melakukan atau mempersiapkan kegiatan lainnya di dalam proyek ini dan tidak terbuang sia-sia.

\section{KESIMPULAN DAN SARAN}

\section{Kesimpulan}

Berdasarkan hasil perhitungan dan analisa pada penelitian ini dapat disimpulkan, sebagai berikut:

1. Hasil analisis dengan metode crew balance chart didapatkan waktu tidak produktif dan koefisien dari pekerja, untuk pekerja area depan hari pertama pekerja 1 didapatkan waktu tidak produktif sebesar 9,711\% dan koefisien sebesar 90,289\% sedangkan untuk pekerja 2 waktu tidak produktif sebesar 24,264\% dan koefisien 75,736\%. Hari kedua area depan, didapatkan waktu tidak produktif dan koefisien sebesar 24,996\% dan 75,004\% sedangkan untuk pekerja 2 sebesar $25,713 \%$ dan 74,287\%. Waktu tidak produktif dan koefisien pekerja untuk area belakang pada hari pertama sebesar $26,978 \%$ dan $73,022 \%$ untuk pekerja A dan untuk pekerja B sebesar $36,415 \%$ dan 63,585\%, sedangkan untuk hari kedua, pekerja A didapatkan sebesar 19,041\% dan 80,959\% dan untuk pekerja B sebesar 48,737\% dan 51,263\%.

2. Hasil produktivitas pekerjaan pemasangan dinding bata di area depan pada hari pertama sebesar $0,9841 \mathrm{~m}^{2} / \mathrm{jam}$ untuk kondisi lapangan dan 1,1855 m²/jam untuk kondisi ideal, pada hari kedua produktivitasnya sebesar 0,9933 $\mathrm{m}^{2} /$ jam untuk kondisi lapangan dan 1,3307 $\mathrm{m}^{2} / \mathrm{jam}$ untuk kondisi ideal. Hasil produktivitas di area belakang pada hari pertama sebesar 1,537 $\mathrm{m}^{2} / \mathrm{jam}$ untuk kondisi lapangan dan 2,2502 $\mathrm{m}^{2} / \mathrm{jam}$ untuk kondisi ideal, pada hari kedua produktivitasnya sebesar $0,7317 \mathrm{~m}^{2} / \mathrm{jam}$ untuk kondisi lapangan dan $1,1067 \mathrm{~m}^{2} / \mathrm{jam}$ untuk kondisi ideal.

\section{Saran}

Berdasarkan penelitian ini terdapat beberapa saran dari peneliti sebagai berikut:

1. Dari hasil penelitian didapatkan bahwa produktivitas pekerja pemasangan dinding bata pada area belakang proyek ini ada yang hampir mencapai 50\%, maka disarankan perlu dilakukan pengawasan yang lebih dari mandor agar pekerjaan dapat diselesaikan tepat waktu sehingga tidak mengganggu pekerjaan lainnya.

2. Bagi peneliti yang akan datang diharapkan megembangkan penelitian ini lebih lanjut pada jenis pekerjaan yang sama tetapi dapat memilih proyek di bangunan gedung dimana pekerja nya pasti lebih terfokus hanya ke satu pekerjaan saja, sehingga waktu pengamatan dapat dilakukan satu hari kerja penuh sehingga data yang ada memiliki waktu yang lebih panjang dan akan mendapatkan hasil yang lebih optimal.

\section{DAFTAR PUSTAKA}

Cahyo, Andi Dwi. "Perbandingan Biaya dan Waktu pada Pelaksanaan Pekerjaan Pasangan Dinding Bata Ringan dan Dinding Bata Merah dengan Metode Time Study." (2016).

Caroline, Denny. "Pengaruh Peningkatan Produktivitas Terhadap Durasi Fabrikasi besi Pada Proyek Indonesia 1 dengan Crew Balance Chart.” (2018).

Ervianto, W I. Manajemen Proyek Konstruksi. Yogyakarta: Andi Offset, 2005.

—. "Pengukuran Produktivitas Kelompok Pekerja Bangunan dalam Proyek Konstruksi." (2008).

Han, F and D Leong. Productivity and Sercive Quality. Singapura: Prentice Hall, 1996.

Handayani, Sri. "Kualitas Batu Bata Merah dengan Penambahan Serbuk Gergaji.” (2010).

Herlina, Indrawati and Misbach. "Mata Kuliah Psikodiagnostik II (Observasi)." Fakultas Ilmu Pendidikan, Universitas Pendidikan Indonesia, 2007.

James J O'brien; Zilly; Robert G. Contractor's management handbook. New York: McMraw-hill inc, 1991.

Jitchaiyaphum, et al. "Cellular lightweight concrete containing high-calcium fly ash and natural zeolite." International Journal of Minerals, Metallurgy and Materials (2013): 462.

Kristiana, Retna and Aan Pujiandi. "Analisa Produktivitas Dinding Bata Ringan Dinding Precast pada Bangunan Gedung Tinggi Hunian.” Rekayasa Sipil Vol.5 No.2 (2016): 81-92. 
Produktivitas Pekerja dalam Pekerjaan Pemasangan

Dinding Bata dengan Metode Crew Balance Chart

Kuprenas, J.A and A.S Fakhouri. A crew balance chart study improving construction productivity. management association of America, 2001.

Mania, Siti. “Observasi Sebagai Alat Evaluasi dalam Dunia Pendidikan dan Pengajaran.” Lentera Pendidikan Vol 11 No 2 (2008): 220-233.

Oxford University Press. Idea and Method of Legal Research. New Delhi: Oxford University Press, 2019.

Rustendi, Iwan. "Produktivitas Pekerjaan Pasangan Batu Bata pada Dinding Rumah Tinggal.” (2011). 